\title{
Calcified thrombosis in the portal system mimicking choledocholithiasis and diagnosed by endoscopic ultrasound
}

A 67-year-old woman with abdominal pain and jaundice for the preceding 6 months was referred for endoscopic ultrasound (EUS) to evaluate the presence of choledocholithiasis. The patient had a history of diabetes, schistosomal infection, and chronic hepatitis $C$ (cirrhotic portal hypertension). A computed tomography (CT) scan showed cholelithiasis, calcified thrombosis in the portal system, and possible choledocholithiasis ( Figs. 1,2). EUS showed cholelithiasis and calcified thrombosis in the portal and splenic veins. Evidence of choledocholithiasis was not observed ( Figs.3-6).

Calcification in the portal vein system has been previously described in patients with longstanding portal hypertension. Demonstration of such calcification on imaging studies is extremely rare. The first case of portal vein calcification was reported by Moberg in 1943 [1]. The calcium deposition has been reported as being observed in well-organized thrombi attached to the interrupted intima in most of the cases described [1-4].

In a clinical review published in 1993, Kawasaki et al. [5] collected data from 21 patients with calcification of the portal venous system reported between 1940 and 1990 . The calcified lesions were found in the portal vein in $100 \%$ of patients, in the splenic vein in $62 \%$, and in the superior mesenteric vein in $33 \%$. All of the patients showed signs and symptoms of portal hypertension. Calcification was identified on imaging examinations and was later confirmed by autopsy, surgery, or angiography.

A knowledge of the possible vascular source of these calcium deposits is important in order to avoid diagnostic confusion with other diseases, such as choledocholithiasis, chronic pancreatitis, pancreatic ductal calcification, pancreatic pseudocyst with parietal calcification, and cystic neoplasm of the pancreas. In addition, recognition of extensive calcification in the wall of the portal vein or its tributaries may have therapeutic significance, because its presence may hinder the creation of a venous anastomosis in a portosystemic shunt [4].

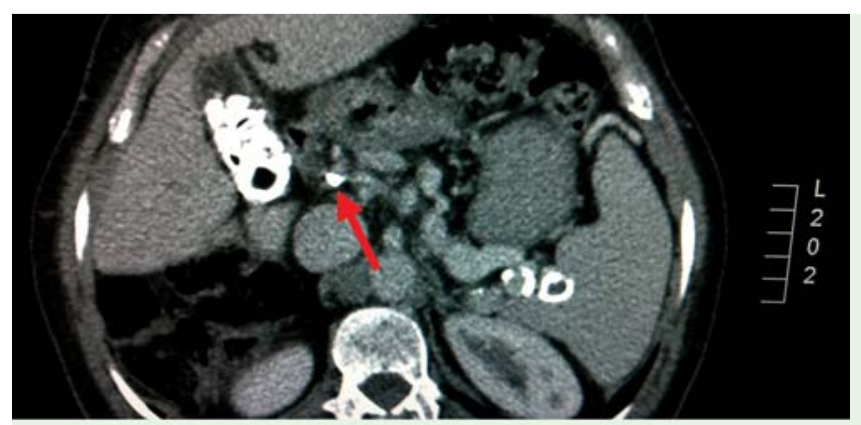

Fig. 1 Computed tomography (CT) scan showing cholelithiasis, calcified thrombosis (arrows) in the portal system, and possible choledocholithiasis, in horizontal section.
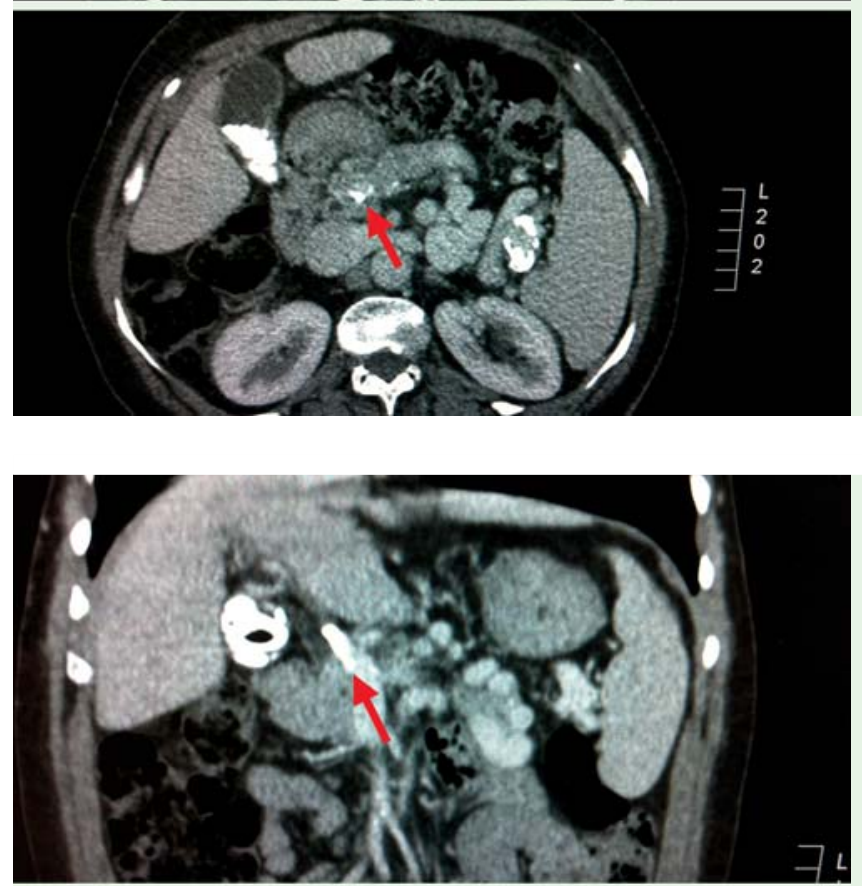

Fig. 2 Computed tomography (CT) scan showing cholelithiasis, calcified thrombosis (arrow) in the portal system, and possible choledocholithiasis, in coronal (top panel) and sagittal (bottom panel) view. 

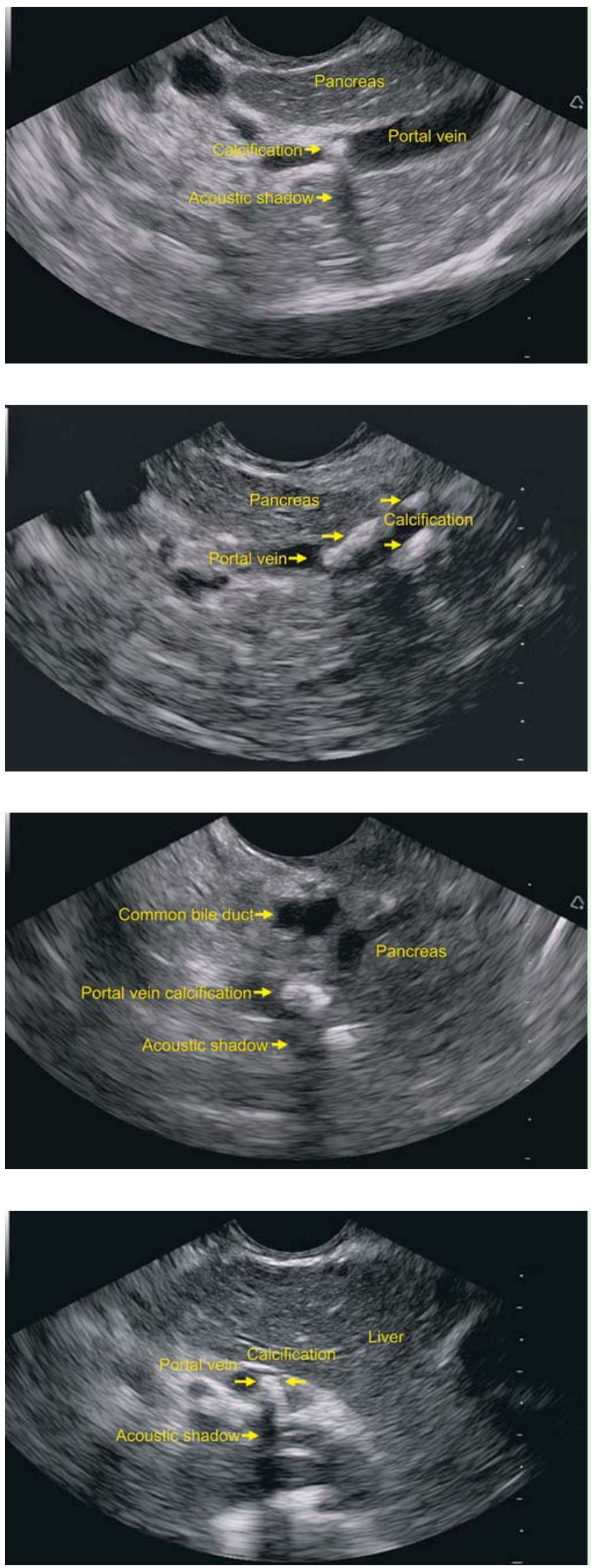

Fig. 3 Endoscopic ultrasound (EUS; stomach view) showing calcified thrombosis in the portal vein and an acoustic shadow.

Fig. 5 Endoscopic ultrasound (EUS; duodenal view) showing calcified thrombosis in the portal vein and main bile duct without stones.

Endoscopy_UCTN_Code_CCL_1AF_2AG_3AD

\section{Competing interests: None}

\section{Augusto Carbonari, Flavio Amaro, Frank Nakao, Osvaldo Araki, Mauricio Assef, Lucio Rossini}

Department of Endoscopy of Santa Casa de São Paulo Hospital and French-Brazilian Centre of Endoscopic Ultrasound

(CFBEUS), São Paulo, Brazil

\section{References}

1 Moberg G. Calcified thrombosis in portal system diagnosed by roentgen examination. Acta Radiol (Stockh) 1943; 24: 374-383

2 Hadar H, Sommer R. Calcification in the portal venous system demonstrated by computed tomography. Eur J Radiol 1983; 3: 187 188

3 Magovern GJ, Muehsam GE. Calcification of the portal and splenic veins. Am J Roentgenol Radium Ther Nucl Med 1954; 71: 84-88

4 Smallwood RA, Davidson JS. Calcification in the portal system. Gastroenterology 1968; 54: $265-270$

5 Kawasaki T, Kambayashi J, Sakon $M$ et al. Portal vein calcification: a clinical review of the last 50 years and report of a case associated with dysplasminogenemia. Surg Today 1993; 23: 176-181

\section{Bibliography}

DOI http://dx.doi.org/

10.1055/s-0034-1365153

Endoscopy 2014; 46: E197-E198

(c) Georg Thieme Verlag KG

Stuttgart · New York

ISSN 0013-726X

\section{Corresponding author \\ Augusto Carbonari, MD}

Department of Endoscopy of Santa Casa de São Paulo Hospital and French-Brazilian Centre of Endoscopic Ultrasound (CFBEUS)

Rua Manuel Figueiredo Landim

600 ap 52A São Paulo

Fig. 6 Endoscopic ultrasound (EUS; stomach view) showing calcified thrombosis (opposing arrows) in the portal vein at the hepatic hilum and an acoustic shadow.

\section{Brazil}

Fax: +55-19-996040645

augustocarbonari@gmail.com 